\title{
Skin Collagen and Thickness in Women with Hirsuties
}

\author{
SAM SHUSTER,* M.B., PH.D., F.R.C.P. ; MARTIN M. BLACK, $\$ M.B., M.R.C.P. ; EVA BOTTOMS, $\ddagger$ B.sC.
}

British Medical fournal, 1970, 4, 772

Cummary: Total skin collagen is greatly increased in $\checkmark$ women with hirsuties. This is presumably due to androgen, whether locally produced or circulating.

\section{Introduction}

We have long suspected that patients with hirsuties have a thickened skin. Since we have shown that skin thickness and skin collagen are directly related (Black et al., 1970a) we measured both skin thickness and total skin collagen content in patients with hirsuties.

\section{Methods}

The patients were all women with hirsuties aged from 17 to 38 years. Eight had the Stein-Leventhal syndrome and in 18 the hirsuties was "idiopathic." Skin thickness was measured in all 26 patients by the radiographic method of Meema et al. (1964) as modified by Black (1969). The results were age-matched and compared with our data for 107 normal women (to be published). Total skin collagen was measured in 25 of the patients by the method of Shuster and Bottoms (1963a) as follows: Skin biopsy specimens were taken from the midpoint of the extensor aspect of the forearm with a highspeed rotary punch of $5 \mathrm{~mm}$. diameter. The specimens were defatted in acetone and then dried to constant weight. After hydrolysis the hydroxyproline content was measured by the method of Woessner (1961). Skin collagen calculated from the hydroxyproline content was expressed in relation to the surface area of the skin biopsy, since this has been shown to be the most satisfactory way to measure total skin collagen (Shuster and Bottoms, 1963a; Shuster et al., 1967a, 1967b). The skin collagen contents of the 25 patients studied were agematched and compared with the results from 62 normal women, which include our previously published normal data (Shuster and Bottoms, 1963a; Shuster et al., 1967a 1967b).

\section{Results}

There is a considerable increase in total skin collagen (Fig. 1). Collagen per fat-free dry weight was also increased, but to a much lesser extent. Skin thickness was increased considerably in some subjects, but taking the group as a whole this increase was not statistically significant. The increase in collagen density (collagen/thickness, Fig. 1) was therefore due to the increased total collagen content of the biopsies.

\section{Discussion}

Despite the clinical hunch which led to this study, skin thickness was not found to be increased in the group as a whole, though it was greatly increased in a few individuals with hirsuties. There are four possible explanations for this: (1) the few who did have a great increase in skin thickness (Fig. 1) made a great impression on us; (2) there may be increased tethering of skin to deeper structures in hirsuties (this occurs in systemic sclerosis, for example, when it gives a false clinical impression of thickness (Black et al., 1970b)); (3) increased density of collagen and consequent "hardness" may have been interpreted as thickness; and (4) we were wrong.

\footnotetext{
- Professor of Dermatology.

+ Registrar.

Senior Research Associate.

\$ Present address: Institute of Dermatologv, London W.C.2.

University Department of Dermatology, Newcastle upon Tyne NE1 4LP.
}

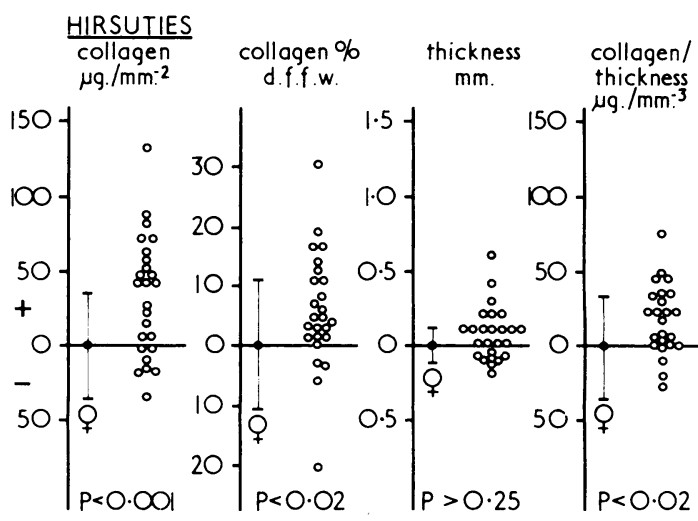

FIG. 1.-Skin collagen (per skin surface area ( $\left.\mu \mathrm{g} . / \mathrm{min}^{-2}\right)$ and per fat-free dry weight (d.f.f.w.)), thickness, and density in patients with hirsuties.

The positive findings are quite clear; there is an increased total skin collagen in patients with hirsuties. The increased collagen density and collagen per fat-free dry weight show that the changes in skin collagen are out of proportion to any change which may have occurred in the ground substance.

Total collagen content was found to be greater in men than in women by Shuster and Bottoms (1963a), and this has since been shown for other species (Shuster and Bottoms, 1963b, 1967; Dickerson and John, 1964). This difference is probably due to androgen, since we have also shown exogenous androgen will increase skin collagen (Black et al., 1970c). There is usually an increase in circulating androgen in patients with "idiopathic" hirsuties and the Stein-Leventhal syndrome (Dignam et al., 1964; Lloyd et al., 1966; Bardin and Lipsett, 1967; and others), and this could therefore explain the increase in skin collagen. Another source of androgen is the skin itself. Androgens are now known to be synthesized and interconverted in normal skin (Wotiz et al., 1956; Rongone, 1966; Gomez and Hsia, 1968; Wilson and Walker, 1969; and others). This could well be important in idiopathic hirsuties since locally produced androgen will have disproportionate local effects, which is precisely the clinical situation of hirsuties without virilism.

We are grateful to the Medical Research Council for a grant to S. S.

REFERENCES

Bardin, C. W., and Lipsett, M. B. (1967). Fournal of Clinical Investigation,

46, 891.

Black, M. M., Bottoms, E., and Shuster, S. (1970a). European fournal of Clinical Investigation, $1,127$.

Black, M. M., Shuster, S., and Bottoms, E. (1970b). British fournal of Dermatology, 83, 552 .

Black, M. M., Shuster, S., and Bottoms, E. (1970c). British Medical fournal, 4,773 .

Dickerson, J. W. T., and John, P. M. V. (1964). Biochemical fournal, 92, 364 Dickerson, J. W. T., and John, P. M. V. I., and Simmer, H. H. (1964). Acto Endocrinologica (Kobenhavn), 45, 254.

Gomez, E. C., and Hsia, S. L. (1968). Biochemistry, 7, 24

Lomez, C. W., et al. (1966). Fournal of Clinical Endocrinology, 26, 314.

Meema, H. E., Shephard, R. H., and Rapoport, A. (1964). Radiology, 82, 411 .

Rongone, E. L. (1966). Steroids, 7, 489

S'nister, S., and Bottoms, E. (1963a). Clinical Science, 25, 487.

Shuster, S., and Bottoms, E. (1963b). Nature, 199, 192.

Shuster, S, and Bottoms, E. (1967). Nature, 214, 599.

Shuster, S. Raffe, E J., and Bottoms, E. (1967a). Lancet, 1, 525.

Shuster, S., Raffle, E. J., and Bottoms, E. (1967b). British fournal of Dermatology, 79, 456.

Wilson, J. D., and Walker, J. D. (1969). Fournal of Clinical Investigation, 48, 371 .

Woessner, I. F. (1961). Archives of Biochemistry and Biophysics, 83, 440

Wotiz, H. H., Mescon, H., Doppel, H., and Lemon, H. M. (1956). Journal of In'estigative Dermatology, 26, 113 . 